\footnotetext{
JURNAL CEMERLANG: Pengabdian pada Masyarakat

P-ISSN 2654-4741 / E-ISSN 2655-7894

Vol. 4, No. 1, Desember 2021, 64 - 75

DOI: https://doi.org/10.31540/jpm.v4i1.1392

PENERBIT: LP4MK STKIP PGRI LUBUKLINGGAU
}

\title{
PELATIHAN PEMBUATAN MINYAK ATSIRI DAUN PSIDIUM GUAJAVA L. MELALUI PROSES DESTILASI DI DESA MEGANG SAKTI III KECAMATAN MEGANG SAKTI Wahyu Arini ${ }^{1}$, Tri Ariani ${ }^{2}$ \\ ${ }^{12}$ Program Studi Pendidikan Fisika, STKIP PGRI Lubuklinggau Jalan Mayor Toha Kelurahan Air Kuti, Kota Lubuklinggau, 31628, Indonesia Email: wahyuarini02@gmail.com
}

Saat ini banyak dikembangkan minyak atsiri aromatik yang dihasilkan dari berbagai jenis daun yang terdapat di Indonesia. Salah satu daun yang berpotensi menghasilkan minyak atsiri aromatik adalah daun jambu biji. Berbagai daun jambu biji telah banyak dimanfaatkan sebagai minyak atsiri, namun ada varietas baru dari daun jambu biji yang belum dimanfaatkan sebagai minyak atsiri yaitu daun jambu kristal. Daun jambu kristal memiliki manfaat yang banyak karena daun jambu kristal mengandung beberapa senyawa volatile dan memilik aroma khas yang kuat, sehingga daun jambu biji berpotensi menghasilkan minyak atsiri. Tanaman jambu kristal menjadi salah satu komoditas unggulan di Desa Megang Sakti III, hal ini di tandai dengan banyaknya perkebunan jambu kristal disepanjang wilayah Kecamatan Megang Sakti III, selain itu pemanfaatan terhadap daun jambu kristal ini masih tergolong biasa-biasa saja, seperti hanya di jadikan sebagai obat diare dan selebihnya tidak di manfaatkan. sehingga menarik minat TIM dalam melaksanakan kegiatan PPM di desa tersebut dengan pelatihan pembuatan minyak atsiri dari daun jambu menggunakan proses destilasi. Minyak atsiri adalah minyak yang diperoleh dari bagian tanaman dengan cara destilasi uap atau destilasi air. Minyak atsiri dari daun jambu kristal sangat potensial digunakan sebagai antimikroba dan antioksidan.

\section{ABSTRACK}

Currently, many aromatic essential oils are developed from various types of leaves found in Indonesia. One of the leaves that have the potential to produce aromatic essential oils is guava leaf. Various guava leaves have been widely used as essential oils, but there is a new variety of guava leaves that has not been used as essential oil, namely crystal guava leaves. Crystal guava leaves have many benefits because crystal guava leaves contain several volatile compounds and have a strong distinctive aroma, so guava leaves have the potential to produce essential oils. The crystal guava plant is one of the leading commodities in Megang Sakti III Village, this is indicated by the many crystal guava plantations throughout the Megang Sakti III District, besides that the use of crystal guava leaves is still relatively mediocre, as if it is only used as a diarrhea medicine and the rest is not used. thus attracting the interest of TIM in carrying out PPM activities in the village by training in making essential oil from guava leaves using the distillation process. Essential oils are oils obtained from plant parts by means of steam distillation or water distillation. Essential oil from crystal guava leaves is very potential to be used as an antimicrobial and antioxidant.

KEYWORDS

Daun Jambu Kristal, Minyak Atsiri

Crystal Guava Leaves, Essential Oil
ARTICLE HISTORY

Received 11 Oktober 2021

Revised 05 November 2021

Accepted 16 Desmber 2021

\section{CORRESPONDENCE Wahyu Arini @wahyuarini02@gmail.com}




\section{JURNAL CEMERLANG: Pengabdian pada Masyarakat P-ISSN 2654-4741 / E-ISSN 2655-7894 \\ Vol. 4, No. 1, Desember 2021, 64 - 75 \\ DOI: https://doi.org/10.31540/jpm.v4i1.1392

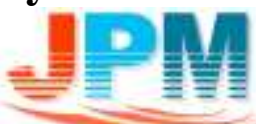 \\ PENERBIT: LP4MK STKIP PGRI LUBUKLINGGAU}

\section{PENDAHULUAN}

Di desa Megang Sakti III Kecamatan Megang Sakti Kabupaten Musi Rawas terdapat banyak sekali tanaman jambu kristal yang tumbuh dan di produksi oleh masyarakat setempat, tentu saja hal ini merupakan hal yang sangat menarik, karena semakin banyak tanaman jambu kristal yang di budidayakan maka akan semakin besar juga peluang dalam memanfaatkan daun jambu kristal sebagai minyak atsiri yang mengandung zat antioksidan dan antimikroba. Dalam hal ini TIM memberikan pelatihan pemanfaatan daun jambu Kristal melalui proses destilasi dalam menghasilkan minyak atsiri. Masyarakat Desa Megang Sakti III khususnya Para Ibu rumah tangga yang tergabung dalam TIM PKK telah lama menunggu kegiatan-kegiatan positif terkait pemanfaatan sumber daya alam maupun potensi lokal yang ada di daerah mereka sehingga dapat membuka wawasan bagi mereka bahwa banyak hal yang bisa di bentuk dan di wujudkan dari kekayaan alam yang mereka miliki, selain itu masyarakat juga nantinya menjadi lebih produktif dan mampu berinovasi dalam mewujudkan masyarakat maju dan berkompeten.

Dalam hal ini Dosen Pendidikan Fisika dari STKIP-PGRI Lubuklinggau bekerjasama dengan masyarakat Desa Megang Sakti III untuk membantu membuka wawasan masyarakat mengenai pemanfaatan sumber daya alam maupun potensi lokal tersebut menjadi sesuatu hal yang lebih berguna bagi kehidupan mereka salah satunya dengan melakukan pelatihan pembuatan minyak atsiri dari daun jambu kristal yang dituangkan dalam kegiatan PPM.
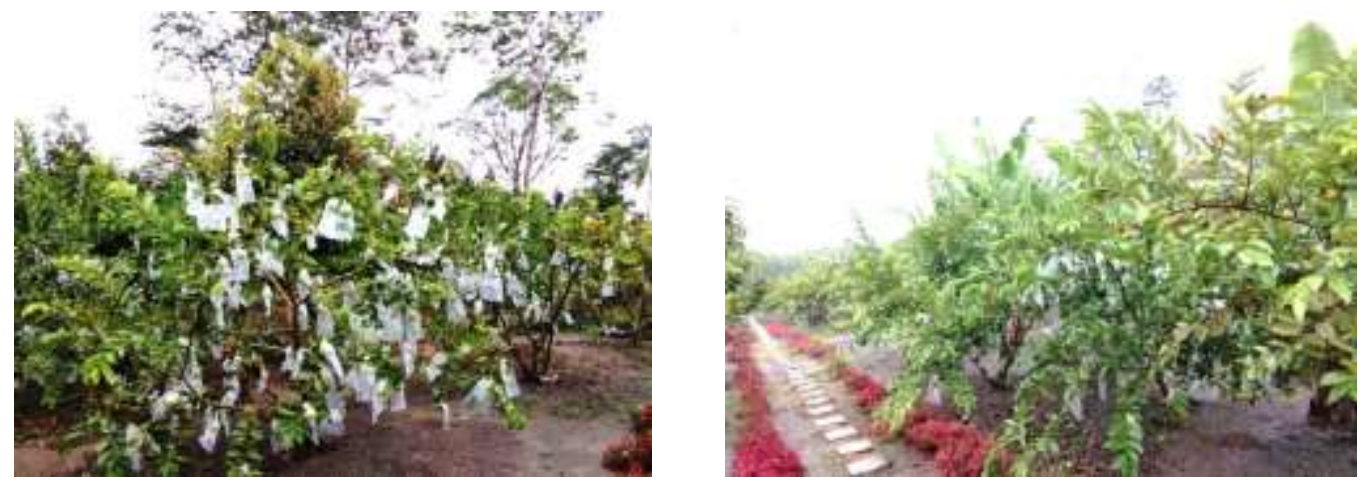

Gambar 1. Perkebunan Daun Jambu Kristal Desa Megang Sakti III 


\section{JURNAL CEMERLANG: Pengabdian pada Masyarakat \\ P-ISSN 2654-4741 / E-ISSN 2655-7894 \\ Vol. 4, No. 1, Desember 2021, 64 - 75 \\ DOI: https://doi.org/10.31540/jpm.v4i1.1392 \\ PENERBIT: LP4MK STKIP PGRI LUBUKLINGGAU}

Daun jambu kristal biasanya hanya di pangkas dan dibuang-buang saja, hanya sedikit sekali yang di manfaatkan warga sebagai obat diare ataupun menjadi daun kering yang siap untuk dijadikan bahan bakar biasa. Dalam perkebunan jambu kristal, limbah daun jambu Kristal yang dihasilkan bisa mencapai puluhan kilo setiap bulannya, dan jarang sekali dimanfaatkan padahal daun jambu kristal juga memiliki banyak kandungan baik yang tidak kalah dengan buahnya, daun jambu kristal memiliki manfaat yang banyak karena daun jambu kristal mengandung beberapa senyawa volatile dan memilik aroma khas yang kuat, sehingga daun jambu kristal berpotensi menghasilkan minyak atsiri. Menurut Weli (2018) beberapa komposisi kimia yang terkandung dalam minyak atsiri daun jambu biji antara lain iso-caryophyllene (33,53\%), veridiflorene (13,00\%), farnesene $(11,65 \%)$, dl-imonene $(9,84 \%)$, dcadinene $(1,75 \%)$, a-copaene $(2,80 \%)$, a-humulene $(3,74 \%)$, dan s-cadinol $(0,08 \%)$. Minyak atsiri dari daun jambu kristal sangat potensial digunakan sebagai antimikroba dan antioksidan. Bahan bakunya sendiri melimpah dikarenakan dapat memanfaatkan hasil dari perawatan jambu kristal dikarenakan setiap 2 sampai 3 hari sekali daun jambu selalu dipangkas agar hasil buah yang diperoleh maksimal.

Minyak atsiri merupukan senyawa terpenoid. Sifat fisik terpenting minyak atsiri adalah sangat mudah menguap pada suhu kamar dan larut dalam lemak. Kandungan minyak atsiri pada daun jambu kristal adalah sebanyak 9,4\%. Minyak asiri, atau dikenal juga sebagai minyak eterik (aetheric oil), minyak esensial (essential oil), minyak terbang (volatile oil), serta minyak aromatik (aromatic oil), adalah kelompok besar minyak nabati yang berwujud cairan kental pada suhu ruang namun mudah menguap sehingga memberikan aroma yang khas. Minyak asiri merupakan bahan dasar dari wangi-wangian atau minyak gosok (untuk pengobatan) alami. Di dalam perdagangan, hasil sulingan (distilasi) minyak atsiri dikenal sebagai bibit minyak wangi. Salah satu proses pembuatan minyak asiri adalah dengan menggunakan teknik destilasi air atau destilasi uap. Sampel tanaman dicampur dengan air. Lalu, campuran tersebut dididihkan. Air dan 


\section{JURNAL CEMERLANG: Pengabdian pada Masyarakat \\ P-ISSN 2654-4741 / E-ISSN 2655-7894 \\ Vol. 4, No. 1, Desember 2021, 64 - 75 \\ DOI: https://doi.org/10.31540/jpm.v4i1.1392 \\ PENERBIT: LP4MK STKIP PGRI LUBUKLINGGAU}

minyak asiri yang terkandung dalam tanaman akan menguap, sementara sisa tanaman yang tidak mengandung minyak asiri akan tetap. Uap campuran air dan minyak asiri didinginkan, lalu tambahkan natrium sulfat anhidrat (Na2SO4) untuk memisahkan air dari minyak atsiri (Sri Budi, 2008).

Minyak asiri bersifat mudah menguap karena titik uapnya rendah. Selain itu, susunan senyawa komponennya kuat memengaruhi saraf manusia (terutama di hidung) sehingga sering kali memberikan efek psikologis tertentu. Setiap senyawa penyusun memiliki efek tersendiri, dan campurannya dapat menghasilkan rasa yang berbeda. Karena pengaruh psikologis ini, minyak asiri merupakan komponen penting dalam aromaterapi atau kegiatan-kegiatan liturgi dan olah pikiran/jiwa, seperti yoga atau ayurveda.

\section{METODE}

Untuk mendukung tujuan tersebut Tim dari STKIP PGRI Lubuklinggau akan melakukan kegiatan dengan dibagi menjadi empat tahapan, yaitu tahap persiapan, tahap pelatihan, tahap perancangan dan pembuatan alat, dan tahap pelaksanaan.

\section{1) Tahap persiapan}

Pada tahap persiapan tim pengabdian pada masyarakat (PKM) melakukan survey pendahuluan untuk melihat kondisi di lapangan mengenai limbah daun jambu kristal yang menumpuk di Desa Megang Sakti III Kecamatan Megang Sakti. Dalam tahap ini TIM mencari permasalahan-permasalahan yang dihadapi oleh warga setempat, yang kemudian TIM mencari solusi terhadap masalah tersebut.

\section{2) Tahap pelatihan/sosialisasi}

Pelatihan ini dilakukan untuk memberikan gambaran tentang cara mengelolah limbah daun jambu kristal menjadi minyak atsiri. Melalui pelatihan ini mitra diajarkan bagaimana cara membuat rangkaian destilasi sebagai proses pengolahan minyak atsiri dari daun jambu kristal. Metode yang digunakan dalam pelatihan ini adalah ceramah, diskusi, dan pembimbingan. 


\section{JURNAL CEMERLANG: Pengabdian pada Masyarakat \\ P-ISSN 2654-4741 / E-ISSN 2655-7894 \\ Vol. 4, No. 1, Desember 2021, 64 - 75 \\ DOI: https://doi.org/10.31540/jpm.v4i1.1392 \\ PENERBIT: LP4MK STKIP PGRI LUBUKLINGGAU}

3) Tahap Perancangan dan pembuatan alat

Tahap ini dilakukan dalam rangka untuk membuat minyak atsiri dengan proses destilasi uap. Tahapan-tahapan yang dilakukan dalam kegiatan ini adalah:

a. Observasi lapangan

Observasi lapangan bertujuan untuk mengetahui lokasi sumber jambu kristal di Desa Megang Sakti III Kecamatan Megang Sakti.

b. Perancangan alat destilasi daun jambu kristal

c. Prosedur penggunaan alat destilasi

d. Pengujian alat, dan

e. Pelatihan pengoperasian alat dan perawatan alat destilasi

4) Tahap Pelaksanaan

Pelaksanaan kegiatan pengabdian memerlukan partisipasi dari mitra untuk keberlangsungan penyelesaian masalah mitra. Partisipasi mitra dalam pelaksanaan program diantaranya (1) memberikan informasi tentang permasalahanpermasalahan yang dihadapi oleh Ibu-ibu PKK terhadap limbah daun jambu kristal; (2) menyediakan tempat untuk pelaksanaan program yang telah disusun oleh tim pelaksana; (3) menyediakan bahan baku seperti daun jambu kristal; (4) ikut serta merancang bangun alat destilasi minyak atsiri; (5) perawatan alat yang telah diberikan oleh Tim Pengabdian; (6) mengikuti kegiatan praktek langsung produksi minyak atsiri dari daun jambu kristal; (7) diskusi dan tanya jawab.

5) Tahap Evaluasi

Tahap terakhir adalah evaluasi. Pada tahap ini dilakukan evaluasi atas hasil yang telah dicapai oleh peserta pelatihan. Masukan dan perbaikan lebih lanjut dapat di lakukan pada tahap ini. Evaluasi diberikan dengan mengumpulkan data yang diperoleh dari kegiatan sosialisasi dan pelatihan. Data diambil dengan menyimpulkan pemahaman warga setempat ketika diberikan wawasan mengenai cara membuat minyak atsiri dari daun jambu kristal serta cara membuat dan menggunakan alat destilasi. 


\footnotetext{
JURNAL CEMERLANG: Pengabdian pada Masyarakat

P-ISSN 2654-4741 / E-ISSN 2655-7894

Vol. 4, No. 1, Desember 2021, 64 - 75

DOI: https://doi.org/10.31540/jpm.v4i1.1392

PENERBIT: LP4MK STKIP PGRI LUBUKLINGGAU
}

\section{HASIL dan PEMBAHASAN}

Berdasarkan kegiatan pengabdian kepada masyarakat yang telah dilaksanakan dengan tahapan awal melakukan observasi pada tanaman jambu Kristal (Psidium Guava.L) di Desa Megang Sakti III Kecamatan Megang Sakti, dengan memperhatikan dan mencari tahu dimana sumber lokasi pembudidayaan serta kuantitas tanaman jambu kristal.

Di desa Megang Sakti III terdapat banyak sekali tanaman jambu kristal yang tumbuh dan di produksi oleh masyarakat setempat, tentu saja hal ini merupakan hal yang sangat menarik, karena semakin banyak tanaman jambu kristal yang di budidayakan maka akan semakin besar juga peluang dalam memanfaatkan daun jambu kristal sebagai minyak atsiri yang mengandung zat antioksidan dan antimikroba. Dalam hal ini TIM memberikan pelatihan pemanfaatan daun jambu Kristal melalui proses destilasi dalam menghasilkan minyak atsiri. Masyarakat Desa Megang Sakti III khususnya Para Ibu rumah tangga yang tergabung dalam TIM PKK telah lama menunggu kegiatan-kegiatan positif terkait pemanfaatan sumber daya alam maupun potensi lokal yang ada di daerah mereka sehingga dapat membuka wawasan bagi mereka bahwa banyak hal yang bisa di bentuk dan di wujudkan dari kekayaan alam yang mereka miliki, selain itu masyarakat juga nantinya menjadi lebih produktif dan mampu berinovasi dalam mewujudkan masyarakat maju dan berkompeten.

Dalam hal ini Dosen Pendidikan Fisika dari STKIP-PGRI Lubuklinggau bekerjasama dengan masyarakat Desa Megang Sakti III untuk membantu membuka wawasan masyarakat mengenai pemanfaatan sumber daya alam maupun potensi lokal tersebut menjadi sesuatu hal yang lebih berguna bagi kehidupan mereka salah satunya dengan melakukan pelatihan pembuatan minyak atsiri dari daun jambu kristal yang dituangkan dalam kegiatan PPM.

https://ojs.stkippgri-lubuklinggau.ac.id/index.php/JPM 

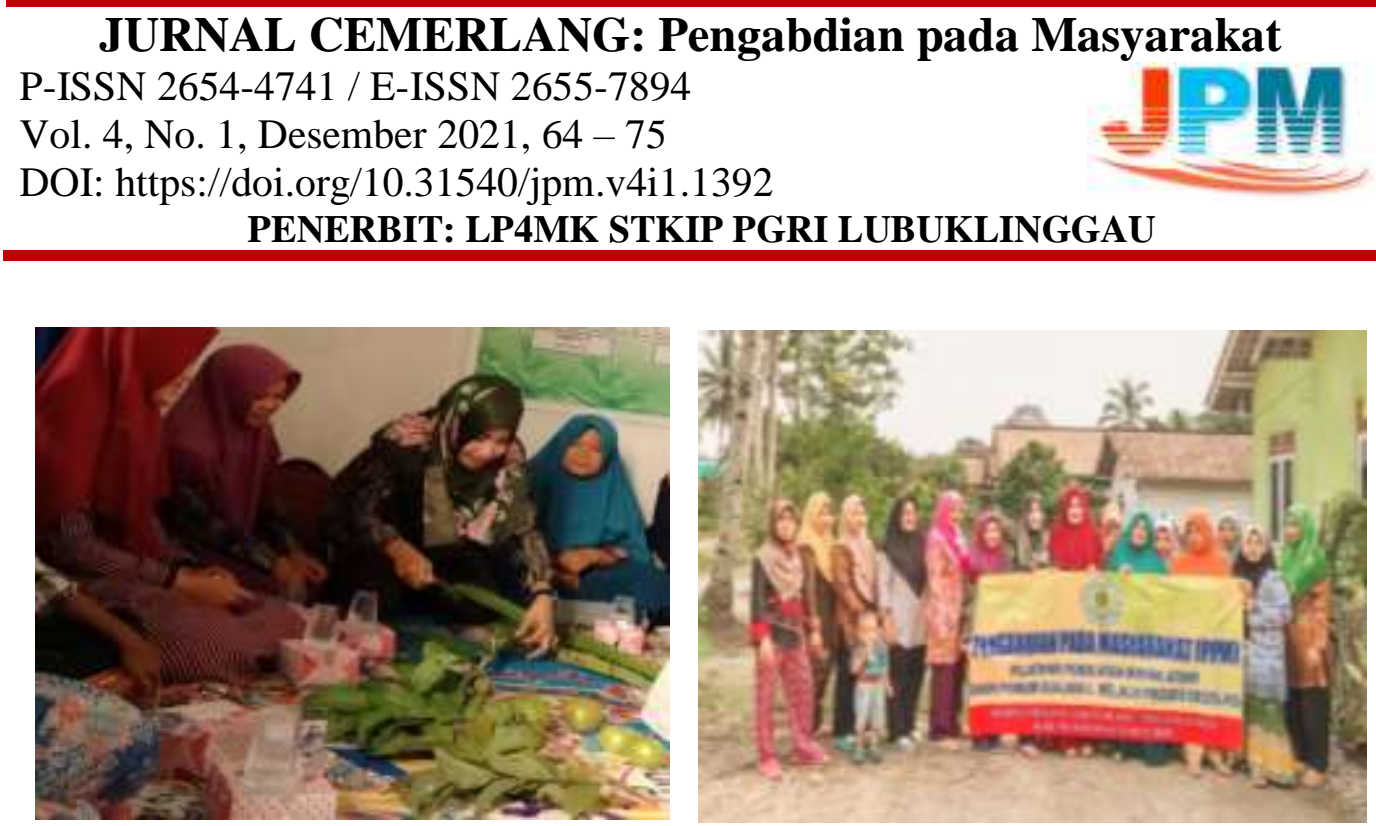

Gambar 2. PPM Pelatihan Pembuatan Minyak Atsiri Daun Jambu Kristal

Daun jambu kristal biasanya hanya di pangkas dan dibuang-buang saja, hanya sedikit sekali yang di manfaatkan warga sebagai obat diare ataupun menjadi daun kering yang siap untuk dijadikan bahan bakar biasa. Dalam perkebunan jambu kristal, limbah daun jambu Kristal yang dihasilkan bisa mencapai puluhan kilo setiap bulannya, dan jarang sekali dimanfaatkan padahal daun jambu kristal juga memiliki banyak kandungan baik yang tidak kalah dengan buahnya, daun jambu kristal memiliki manfaat yang banyak karena daun jambu kristal mengandung beberapa senyawa volatile dan memilik aroma khas yang kuat, sehingga daun jambu kristal berpotensi menghasilkan minyak atsiri. Menurut Maulana (2019) beberapa komposisi kimia yang terkandung dalam minyak atsiri daun jambu biji antara lain iso-caryophyllene (33,53\%), veridiflorene $(13,00 \%)$, farnesene $(11,65 \%)$, dl-imonene $(9,84 \%)$, dcadinene $(1,75 \%)$, acopaene $(2,80 \%)$, a-humulene $(3,74 \%)$, dan s-cadinol $(0,08 \%)$. Minyak atsiri dari daun jambu kristal sangat potensial digunakan sebagai antimikroba dan antioksidan. Bahan bakunya sendiri melimpah dikarenakan dapat memanfaatkan hasil dari perawatan jambu kristal dikarenakan setiap 2 sampai 3 hari sekali daun jambu selalu dipangkas agar hasil buah yang diperoleh maksimal.

Minyak atsiri merupukan senyawa terpenoid. Sifat fisik terpenting minyak atsiri adalah sangat mudah menguap pada suhu kamar dan larut dalam lemak. 


\section{JURNAL CEMERLANG: Pengabdian pada Masyarakat \\ P-ISSN 2654-4741 / E-ISSN 2655-7894 \\ Vol. 4, No. 1, Desember 2021, 64 - 75 \\ DOI: https://doi.org/10.31540/jpm.v4i1.1392 \\ PENERBIT: LP4MK STKIP PGRI LUBUKLINGGAU}

Kandungan minyak atsiri pada daun jambu kristal adalah sebanyak 9,4\%. Minyak asiri, atau dikenal juga sebagai minyak eterik (aetheric oil), minyak esensial (essential oil), minyak terbang (volatile oil), serta minyak aromatik (aromatic oil), adalah kelompok besar minyak nabati yang berwujud cairan kental pada suhu ruang namun mudah menguap sehingga memberikan aroma yang khas. Minyak asiri merupakan bahan dasar dari wangi-wangian atau minyak gosok (untuk pengobatan) alami.

Di dalam perdagangan, hasil sulingan (distilasi) minyak atsiri dikenal sebagai bibit minyak wangi. Salah satu proses pembuatan minyak asiri adalah dengan menggunakan teknik destilasi air atau destilasi uap. Sampel tanaman dicampur dengan air. Lalu, campuran tersebut dididihkan. Air dan minyak asiri yang terkandung dalam tanaman akan menguap, sementara sisa tanaman yang tidak mengandung minyak asiri akan tetap. Uap campuran air dan minyak asiri didinginkan, lalu tambahkan natrium sulfat anhidrat (Na2SO4) untuk memisahkan air dari minyak atsiri (Zulharmita, 2013).

Minyak asiri bersifat mudah menguap karena titik uapnya rendah. Selain itu, susunan senyawa komponennya kuat memengaruhi saraf manusia (terutama di hidung) sehingga sering kali memberikan efek psikologis tertentu. Setiap senyawa penyusun memiliki efek tersendiri, dan campurannya dapat menghasilkan rasa yang berbeda. Karena pengaruh psikologis ini, minyak asiri merupakan komponen penting dalam aromaterapi atau kegiatan-kegiatan liturgi dan olah pikiran/jiwa, seperti yoga atau ayurveda.

Sebagaimana minyak lainnya, sebagian besar minyak asiri tidak larut dalam air dan pelarut polar lainnya. Dalam parfum, pelarut yang digunakan biasanya alkohol. Dalam tradisi timur, pelarut yang digunakan biasanya minyak yang mudah diperoleh, seperti minyak kelapa. Secara kimiawi, minyak asiri tersusun dari campuran yang rumit berbagai senyawa, tetapi suatu senyawa tertentu biasanya bertanggung jawab atas suatu aroma tertentu. Sebagian besar minyak 


\section{JURNAL CEMERLANG: Pengabdian pada Masyarakat \\ P-ISSN 2654-4741 / E-ISSN 2655-7894 \\ Vol. 4, No. 1, Desember 2021, $64-75$ \\ DOI: https://doi.org/10.31540/jpm.v4i1.1392 \\ PENERBIT: LP4MK STKIP PGRI LUBUKLINGGAU}

asiri termasuk dalam golongan senyawa organik terpena dan terpenoid yang bersifat larut dalam minyak (lipofil), (Silva, 2018).

Sebagian besar produksi penyulingan minyak atsiri (essential oil) diproduksi menggunakan metode yang sangat sederhana yaitu destilasi uap. Metode ini paling sering dipakai oleh industri kecil minyak atsiri karena penanganannya mudah dan menggunakan peralatan yang sederhana. Teknologi produksi minyak atsiri yang banyak digunakan adalah destilasi uap yang dapat dilakukan dengan tiga macam teknik yaitu hidrodestilasi, destilasi dengan uap basah (destilasi uap-air) dan dengan uap "kering”(dry steam). Dalam pelatihan pembuatan minyak atsiri daun jambu Kristal, TIM menggunakan proses destilasi uap-air karena prosesnya mudah dan terjangkau bagi masyarakat.

Laju destilasi mencerminkan banyaknya uap yang terkondensasi menjadi fasa cair selama selang waktu tertentu, misalnya satu jam. Nilai ini sebanding dengan jumlah uap air yang melewati bahan dalam wadah destilasi. Makin besar laju destilasi maka banyaknya uapair yang melewati bahan pada setiap satuan waktu makin besar. Hal ini berarti bahwa laju aliran uap air yang melewati bahan juga makin cepat. Dengan demikian maka pada laju destilasi yang makin besar, yang berakibat laju alir uap air makin cepat, maka waktu kontak antara uap air dengan bahan dalam wadah menjadi makin pendek.

Selama proses destilasi uap,yang dapat terdestilasi bersama uap air hanya minyak atsiri yang berada di permukaan bahan. Agar sebanyak mungkin minyak atsiri yang ikut terdestilasi bersama uap air maka tekanan parsial uap minyak atsiri harus setinggi mungkin. Hal ini hanya dapat dicapai bila suhu minyak atsiri sama dengan suhu uap air. Bila waktu kontak antara bahan dengan uapairterlalu pendek maka,karena belum dicapai keadaan setimbang, suhu bahan (dan suhu minyak atsiri yang terdapat pada bahan tersebut) lebih rendah daripada suhu uap air. Akibatnya tekanan uap minyak atsiri menjadi lebih rendah daripada tekanan uap pada suhu uap air, sehingga uap minyak atsiri yang terkondensasi menjadi lebih sedikit yang 


\section{JURNAL CEMERLANG: Pengabdian pada Masyarakat \\ P-ISSN 2654-4741 / E-ISSN 2655-7894 \\ Vol. 4, No. 1, Desember 2021, 64 - 75 \\ DOI: https://doi.org/10.31540/jpm.v4i1.1392 \\ PENERBIT: LP4MK STKIP PGRI LUBUKLINGGAU}

selanjutnya mengakibatkan perolehan minyak atsiri menjadi lebih rendah. Walaupun demikian masih ada hal lain yangdapat menurunkan perolehan minyak atsiri.

Minyak atsiri yang berada di bagian dalam bahan akan terdestilasi bersama uap air setelah terdifusi ke permukaan bahan. Bila laju difusi ini lambat maka,walaupun pada laju destilasi yang cepat, minyak atsiri yang terdestilasimenjadi sangat sedikit. Karena jumlahnya sangat sedikit maka minyak atsiri yang terdapat dalam destilatj umlahnya masih belum melewati kelarutan minyak tersebut dalam air destilat. Pada kondisi ini air destilat sudah jernih dan oleh sebab itu destilasi dihentikan.Akan tetapi bila laju destilasi diperlambat, sehingga waktu untuk berdifusi cukup bagi minyak atsiri mencapai dan terkumpul pada permukaan bahan, maka minyak atsiri yang terdestilasi menjadi cukup banyak.

Dari hasil destilasi daun jambu kristal menjadi minyak atsiri, untuk $1 \mathrm{~kg}$ daun jambu kristal dapat menghasilkan kurang lebih $50 \mathrm{ml}$ minyak atsiri. Selain itu kegiatan pelatihan pembuatan minyak atsiri daun psidium guajava l. melalui proses destilasi di Desa Megang Sakti III Kecamatan Megang Sakti Kabupaten Musi Rawas ini juga mendapatkan apresiasi yang besar dari warga Desa Megang Sakti III, mereka bangga desanya dijadikan objek pengabdian kepada masyarakat dan pelaksanaan pelatihan pembuatan minyak atsiri daun psidium guajava $l$, karena dengan kegiatan ini, wawasan warga menjadi meningkat dan semakin menyadari bahwa sangat penting merecycle potensi alam yang ada untuk menghasilkan produk yang bermanfaat besar dalam menjaga kesehatan maupun di kehidupan sehari-hari. Selain itu, warga menganggap kehadiran mahasiswa dan dosen-dosen juga diharapkan bisa memotivasi warga desa untuk menyekolahkan anak-anaknya setinggi mungkin dengan menimba ilmu, karena warga Desa Megang Sakti III Kecamatan Megang Sakti sangat yakin kedepan desanya akan lebih maju dengan IPTEK yang terus di sosialisasikan, dikembangkan dan di implementasikan di desa mereka. 


\footnotetext{
JURNAL CEMERLANG: Pengabdian pada Masyarakat

P-ISSN 2654-4741 / E-ISSN 2655-7894

Vol. 4, No. 1, Desember 2021, 64 - 75

DOI: https://doi.org/10.31540/jpm.v4i1.1392

PENERBIT: LP4MK STKIP PGRI LUBUKLINGGAU
}

\section{SIMPULAN}

Beberapa kesimpulan yang dapat dirumuskan dari PPM Pelatihan Pembuatan Minyak Atsiri Daun Psidium Guajava L. Melalui Proses Destilasi Di Desa Megang Sakti III Kecamatan Megang Sakti yaitu :

1) Tanaman jambu kristal menjadi salah satu komoditas unggulan di Desa Megang Sakti III, hal ini di tandai dengan banyaknya perkebunan jambu kristal di wilayah Kecamatan Megang Sakti III.

2) daun jambu kristal juga memiliki banyak kandungan baik yang tidak kalah dengan buahnya, daun jambu kristal memiliki manfaat yang banyak karena daun jambu kristal mengandung beberapa senyawa volatile dan memilik aroma khas yang kuat, sehingga daun jambu kristal berpotensi menghasilkan minyak atsiri. Dalam $1 \mathrm{~kg}$ daun jambu kristal dapat menghasilkan minyak atsiri kurang lebih sebanyak $50 \mathrm{ml}$, minyak atsiri dari daun jambu kristal juga sangat potensial digunakan sebagai antimikroba dan antioksidan berdasarkan penelitian sebelumnya.

3) Daun jambu kristal dapat menghasilkan minyak atsiri, sehingga masyarakat menyadari bahwa banyak hal bermanfaat yang bisa di peroleh dari daun jambu kristal selain buahnya.

\section{DAFTAR PUSTAKA}

Ariati, A.S., dan Sulistyowati, E. (2016). Pemanfaatan Ekstrak Daun Jambu Biji (Psidium guajava L.) sebagai Antioksidan Minyak Kelapa Krengseng. Jurusan Pendidikan Kimia, FMIPA Universitas Negeri Yogyakarta. Yogyakarta.

Daud, M. F., Sadiyah, E. R., \& Rismawati, E. (2011). Pengaruh Perbedaan Metode Ekstraksi Terhadap Aktivitas Antioksidan Ekstrak Etanol Daun Jambu Biji (Psidium guajava L.) Berdaging Buah Putih. Prosiding SNaPP, 2(1), 55-62.

Fratiwi, Y. (2015). The Potential of Guava Leaf (Psidium guajava L.) For Diarrhea. J MAJORITY, 4(1), 113-118. 


\section{JURNAL CEMERLANG: Pengabdian pada Masyarakat \\ P-ISSN 2654-4741 / E-ISSN 2655-7894 \\ Vol. 4, No. 1, Desember 2021, 64 - 75 \\ DOI: https://doi.org/10.31540/jpm.v4i1.1392 \\ PENERBIT: LP4MK STKIP PGRI LUBUKLINGGAU}

Hapsoh, \& Hasanah, Y. (2011). Budidaya Tanaman Obat dan Rempah. Medan: USU Press.

Maulana, E. A., Asih, I. A., \& Arsa, M. (2016). Isolasi dan Uji Aktivitas Antioksidan Senyawa Flavonoid dari Ekstrak Daun Jambu Biji Putih (Psidium guajava L.). Jurnal Kimia, 10(1), 161-168.

Mittal, P., Gupta, V., Kaur , G., Gaug, A., \& Singh, A. (2010). Phytochemistry and Pharmacological Activities of PSidium guajava. IJPSR, 1(1), 9-19.

Priyono, K., Rudi, F., \& Rachmawati, S. (2018). Pengambilan Minyak Atsiri dari RImpang Jahe Merah menggunakan Metode Destilasi Uap dan Ekstraksi Air dengan Pemanas Microwave. Prosiding Seminar Nasional Teknik Kimia "Kejuangan" Pengembangan Teknologi Kimia untuk Pengolahan Sumber Daya Alam Indonesia. Yogyakarta: Universitas Pembangunan Nasional "Veteran" Yogyakarta. 1-7'

Silva, E. J., Silva, V. P., Alves, C. C., Alves , J. M., Souchie, E. L., \& Barbosa, L. C. (2018). Chemical Composition of the Essential OIl of Psidium guajava Leaves and its Toxicity Against Sclerotinia sclerotiorum. Semina: Ciências Agrárias, Londrina, 39(2), 865-874.

Sri Budi. 2008. Komponen kimia minyak atsiri kemangi dan Ruku-Ruku. Bidang Botani. Cibinong Science Center-LIPI.

Yulisma, L. (2018). Uji Efektivitas Antibakteri Ekstrak Daun Jambu Biji Lokal (Psidium guajava L.) terhadap Pertumbuhan Staphylococcus Aureus dan Bacilus Subtilis secara In Vitro. Quagga, 10(2), 1-6.

Zulharmita, Kasypiah, U., \& Rivai, H. (2013). Pembuatan dan Karakterisasi Ekstrak Kering Daun Jambu Biji (Psidium guajava L.). Jurnal Farmasi Higea, 5(1), 120-127. 